\section{¿ES EL RELATIVISMO EL LÍMITE DE MI MUNDO?}

\author{
IS RELATIVISM THE LIMIT OF MY WORLD?
}

\author{
JONATHAN ELIZONDO OROZCO ${ }^{1}$ \\ (Universidade Federal de Santa Catarina, Brasil)
}

\begin{abstract}
Que el mundo es $m i$ mundo es algo que se muestra en que los límites del lenguaje (del solo lenguaje que yo entiendo) significan los límites de mi mundo. TLP, 5.62. Es por ello por lo que no puede haber proposiciones de ética.

Las proposiciones no pueden expresar nada que sea superior. TLP, 6.42 .
\end{abstract}

\section{RESUMEN}

En el Tractatus Logico-Philosophicus, Wittgenstein colocó la Ética entras las cosas que nuestro lenguaje no puede expresar. Posteriormente, en las Investigaciones Filosóficas él abrió las posibilidades de significación, lo que hizo con que se especulará sobre la alternativa de captar o expresar juicios éticos. Si esto fuera posible surgen varias preguntas: ¿implica esto un cognitivismo metaético? Si se relativizaron las condiciones de expresividad en el lenguaje, ¿implica esto un relativismo ético o, inclusive, un tipo de subjetivismo? En este artículo intentaré argumentar primero contra aquellos que defienden un relativismo ético a partir de la segunda etapa wittgensteiniana, y posteriormente defenderé que los detractores del relativismo ético que utilizan las Investigaciones Filosóficas como arma en sus argumentos, están igualmente equivocados. Mi propuesta es que no existe mayor prueba en este libro de que Wittgenstein abrió la posibilidad para que el lenguaje exprese lo "Superior" [Höheres], y que la aplicación de los nuevos conceptos que introdujo no nos permitiría defender un relativismo ético, sino que un tipo de relativismo epistemológico que puede ser ampliado o utilizado por la metaética.

Palabras clave: Wittgenstein. Etica. Relativismo.

\begin{abstract}
In his book Tractatus Logico-Philosophicus, Wittgenstein put ethics among the things that our language cannot grasp. Later, in the Philosophical Investigations he extended the possibilities of meaning, which resulted in some speculations about an alternative way to grasp or to express ethical judgements. If this is possible, then some questions arise: Does this imply a Metaethical Cognitivism? If the conditions of expression in the language have been relativized, does this imply an ethical relativism or, even, a type of subjectivism? In this article, I will try to argue first against those who defend an ethical relativism using Wittgenstein's later philosophy and, after this, I will defend that the opponents of ethical relativism that use the Philosophical Investigations as a weapon in their arguments, are also wrong. My suggestion is that there is no prove in that book that shows that Wittgenstein opened the possibility for language to express the "Superior" [Höheres], and that the application of the concepts he introduced will not let us defend an ethical relativism, but some sort of epistemic relativism that could be amplified or used by Metaethics.
\end{abstract}

Key words: Wittgenstein. Ethics. Relativism. 


\section{Introducción}

En el Tractatus Logico-Philosophicus, Wittgenstein presentó una distinción entre decir [sagen] y mostrar [zeigen]. En resumen aquellas cosas que pueden ser dichas son cosas que pueden ser valoradas como falsas o verdaderas. Aquellas que pueden ser mostradas tienen como característica, entre otras, que no pueden ser representadas como falsas o verdaderas. Varias cosas entran en la lista de lo que no puede ser dicho y solo mostrado, y el nombre genérico que Wittgenstein da a estas cosas es Lo Místico. Entre las cosas que pertenecen a lo Místico está la ética, y si caracterizamos al no-cognitivismo metaético como la vertiente que sostiene que los juicios éticos no son capaces de ser valorados como falsos o verdaderos, entonces, Wittgenstein en el Tractatus es una no-cognitivista.

Posteriormente, en las Investigaciones Filosóficas Wittgenstein flexibilizó las condiciones de significación del lenguaje, ahora no son las reglas de la lógica formal que delimitan el ámbito de lo decible y lo mostrable. Son las reglas del contexto en el cual las palabras son usadas las que determinarán si una expresión tiene o no significación. A partir de esa apertura, varios filósofos han defendido que se sigue un relativismo ético, pues la significación de las palabras que se usan en la ética será adquirida dentro de determinado contexto. Existen otros filósofos que han atacado esa posición y sostienen, a partir de Wittgenstein, que el relativismo ético no se sigue.

Considero que en la mayoría de los casos se pasa por alto varias distinciones importantes, entre ellas que la mayoría, si no todas, de las aseveraciones de Wittgenstein sobre ética son en el ámbito de la metaética. Eso significa que, en la nomenclatura del Tractatus Logico-Philosophicus, eran contrasentidos [Unsinnige], y en la nomenclatura de las Investigaciones Filosóficas, son proposiciones gramaticales. En el presente artículo intentaré argumentar, teniendo está observación presente, que no se sigue de las mudanzas introducidas por Wittgenstein en las Investigaciones que él defendiera, o que se deba defender a partir de ese libro, un relativismo ético.

Mi propuesta es que es coherente con el espíritu de las Investigaciones la exposición que Wittgenstein hace en el Tractatus y la Conferencia sobre ética, a saber: la ética es inexpresable, ella está fuera de este mundo, ella es una experiencia mística. En otras palabras, considero que Wittgenstein no dejó de ser místico en cierto sentido, y que para él la ética puede ser una experiencia, pero ella no puede ser expresada, y por 
ende, él continúa siendo un no-cognitivista metaético, pero esto no implica que se haya convertido en un relativista. Recordemos que el propio Wittgenstein nos alertó, en el prefacio de las Investigaciones Filosóficas, que sus nuevos pensamientos deben ser vistos teniendo como "trasfondo" su "viejo modo de pensar"

Para mí, el relativismo que puede ser defendido a partir de las Investigaciones puede ser llamado de relativismo epistemológico, que es congruente con una postura que defienda que hay saberes expresables y otros no. Para intentar construir mi argumento, primero recordaré el no-cognitivismo del Tractatus y de la Conferencia; posteriormente haré un resumen de la abertura que hace las Investigaciones, enfocándome más en las nociones de forma de vida y gramática a partir de la lectura de Bernard Williams y Hillary Putnam; después utilizaré las exposiciones de dos filósofos (Simon Blackburn y Richard Rorty) que han usado Wittgenstein para defender el relativismo ético, para llamar la atención de lo que considero correcto o equivocado en sus exposiciones; finalmente, haré mis consideraciones finales respecto a la postura que, creo, es la más correcta desde la perspectiva wittgensteiniana frente al relativismo ético. Para elaborar mi punto principal, utilizaré también pasajes de los libros Cultura y Valor, Sobre la Certeza y Zettel.

\section{Lo Superior}

Después de que la famosa carta a Ludwig Von Ficker ${ }^{2}$ fue publicada la importancia que Wittgenstein dio a la ética durante su vida comenzó a ser ampliamente aceptada. En la carta, por lo menos queda claro que el Tractatus tuvo como punto central a la ética ${ }^{3}$. Se puede concluir, entonces, que la preocupación de Wittgenstein por trazar los límites de lo decible, es en realidad dirigida a trazar los límites de lo indecible (lo que él ya había adelantado en el prefacio del libro). Eso que es indecible, que solamente es mostrable es lo místico ("Lo místico no consiste en cómo es el mundo, sino en que sea", TLP, 6.44. "Existe en efecto lo inexpresable. Tal cosa resulta ella misma manifiesta; es lo místico", TLP, 6.522.). Entre las cuestiones que pertenecen a ese místico inexpresable está la ética: "Es por ello por lo que no puede haber proposiciones éticas. Las proposiciones no pueden expresar nada que sea Superior [Höheres]”, TLP, 6.42. La ética está fuera del mundo, ella se ocupa de valores que no están en él: "Es claro que la ética no consiente en que se la exprese. La ética es transcendental. (Ética y estética son uno y lo mismo)" (TLP, 6.421). 
Siguiendo la línea del Tractatus en la Conferencia sobre ética, Wittgenstein torna más explícitos sus argumentos. Él caracteriza aquello que podemos llamar de valor absoluto y aquello que podemos llamar de valor relativo. Sin abrazar una definición precisa de ética, Wittgenstein la caracteriza como "la investigación de lo que es valorizado, o, de lo que es verdaderamente importante, o..., del significado de la vida, o de lo que hace la vida valer la pena ser vivida, o de la manera correcta de vivir" (LE, p. 1). Los valores absolutos son éticos y los relativos triviales. Si analizados, los valores relativos acaban revelándose como juicios respecto a un determinado valor contextual (LE: p.4). Los valores absolutos se encuentran fuera de este mundo (LE: p.3), y nuestro lenguaje no es capaz de expresarlos: "La ética, si alguna cosa, es supernatural y nuestras palabras solamente expresan hechos, así como una taza de té solamente contendría una taza de té llena de agua si se vertiera un galón sobre ella" (LE: p.5). Intentar expresar aquellos valores absolutos es un error, pues es parte de la "esencia misma" de ellos el ser inexpresables; intentar hacerlo es intentar "ir más allá del mundo y eso es decir más allá del lenguaje significativo". Si el límite del lenguaje es el límite de mi mundo, y los valores no son parte del mundo, intentar expresarlos es "ir en contra de los límites del lenguaje" (LE: p.7).

Este no-cognitivismo agresivo no da pie para defender el escepticismo ni el subjetivismo. Contra el escepticismo, podemos utilizar el aforismo (TLP, 6.51) en el cual Wittgenstein crítica el escepticismo en general. Él explica con claridad que lo que el escéptico plantea no podrá ser refutado, no porque él tenga razón, sino porque las preguntas que él plantea son sobre cuestiones que solamente puede ser mostradas. La pregunta ¿existen valores éticos?, y su respuesta son contrasentidos, o sea, no es una pregunta que se pueda hacer ni que se puede responder. Recordemos también el aforismo TLP, 6.522 transcrito encima ("Existe lo inexpresable"), en el cual Wittgenstein expone de manera explícita que "existe" aquello que es lo místico, o sea, no se dice que NO existe lo inexpresable, si no que existe, pero no se le puede expresar. No se sigue un escepticismo a partir del Tractatus.

Contra el subjetivismo, en la Conferencia al referirse que los valores éticos no son estados mentales o reducibles a ellos, el propio Wittgenstein dijo: "Pero lo que quiero decir es que mientras entendamos un estado mental como un hecho descriptible, éste no es bueno ni malo en sentido ético" (LE: p.5). Wittgenstein aclara dos cuestiones en este comentario. La primera es que él no está argumentando que aquello que es 
bueno o malo sea un estado mental subjetivo. Segundo, que si un estado mental fuese descriptible, como lo son los hechos, aun así no se podría determinar si ese estado mental es bueno o malo en el sentido ético.

Ya en las Investigaciones Filosóficas, con la introducción de las nociones de juegos de lenguajes, gramática, parecidos de familia y forma de vida, Wittgenstein parece haber superado la distinción entre decir y mostrar. Como él evitó dar una definición de esas nociones, ellas se han prestado a varias interpretaciones. No voy a discutir las diferentes lecturas que se hacen de ellas aquí, pero me interesa exponer mi lectura de manera resumida: la significación de las palabras se da por su uso (IF, § 7), el lenguaje es un instrumento del cual utilizamos (IF, § 569), la filosofía continúa siendo una actividad, pero ella pasa a ser descriptiva (IF, §124), existen reglas (que podemos llamar gramaticales) que regulan los lances de los juegos de lenguaje, lo que significa que no "vale todo" (IF, § 90), el concepto de forma de vida es una extensión plural del “yo" transcendental del Tractatus (IF, 23).

El último punto señalado en el párrafo anterior es mejor expuesto por Bernard Williams en el décimo segundo capítulo de su libro Suerte Moral ${ }^{4}$. Para Williams, en la apertura que da a las condiciones de sentido en las Investigaciones con el concepto de forma de vida, Wittgenstein no se aleja mucho del yo transcendental del Tractatus (TLP, 5.631; TLP, 5.64, TLP, 5.641). Para él, podemos hacer una analogía entre el plural de la primera persona y la perspectiva transcendental del singular de la primera persona. La proposición del aforismo 5.6 expresada en el plural diría: "El límite de nuestro lenguaje es el límite de nuestro mundo", y ella no puede ser tomada como una simple tautología ni como una aseveración empírica (WILIAMS, 1991, p. 151).

Quisiera llamar la atención que, desde mi lectura de las Investigaciones, la distinción entre decir y mostrar no es completamente abandonada. Si la función de la gramática es describir el uso de los signos, pero no explicarlos (IF, § 496), significa que las reglas o proposiciones gramaticales pasan a tomar el lugar de los contrasentidos [Unsinnige] del Tractatus. No que ellas vayan contra el sentido del lenguaje, pero su función es mostrar cómo están siendo utilizados los signos en los lances de los juegos de lenguaje. Si preguntásemos sobre la regla que regula la regla gramatical, peligramos de caer en un regreso al infinito y esto es algo que Wittgenstein ciertamente quiso evitar (IF, $\S 84$ ). Si la filosofía no es una actividad explicativa y sí descriptiva (IF, § 109; IF, § 126 ; IF, $\S 127$ ), apuntar para las reglas que regulan los signos de las reglas que regulan 
los signos parece ir en contra de esta postura wittgensteiniana, pues en vez de aceptar que esas reglas gramaticales simplemente están describiéndonos como están siendo usados los signos en los lances, estaríamos intentando regularlas. También ese tipo de análisis parece implicar la necesidad de un metalenguaje, o de un lenguaje de orden superior, y esa idea no la encontramos en Wittgenstein, a no ser como lo que él llama simplemente de "filosofía". ¿Significa que las reglas gramaticales no están "presas" a la reglas del lenguaje”? ¡No! El propio Wittgenstein no negaría que podemos preguntar sobre la gramática de la gramática, pero aquí no estamos haciendo nada más que filosofía, con la condición de no intentar decir cómo debe ser la gramática. La pregunta que cabe es si esto sirve de algo.

En la misma línea de exposición, Hilary Putnam, en el quinto capítulo de su libro Razón, Verdad e Historia ${ }^{5}$, al argumentar en contra de la posibilidad de preguntar sobre la posibilidad de la racionalidad sobre las reglas que determinan la racionalidad (o sea, sobre el significado de las reglas que determinan el significado), alega que Wittgenstein utilizó lo que Putnam llama "argumento transcendental": argumentar que la naturaleza de la racionalidad es una actividad que presupone una noción de justificación racional más amplia que la racionalidad institucionalizada (PUTNAM, 1981, p. 121). Desde mi lectura, esa justificación es nuestra forma de vida leída como lo hace Williams (expuesta supra).

Concuerdo con esta lectura de Putnam, y también con su exposición al alegar que no podemos preguntar sobre la racionalidad de los criterios de racionalidad, pues o incurrimos en argumento circular, o en un regreso al infinito. En algún momento debemos parar y ese momento de parar en el análisis es cuando topamos con las reglas gramaticales que constituyen el juego de lenguaje respectivo, y que desde mi lectura, solamente pueden ser mostradas. También comparto la lectura de Putnam (que es concordante con de Williams) que así como en el Tractatus Wittgenstein atacó, por medio del "yo" transcendental, el solipsismo, en las Investigaciones con la noción de forma de vida intenta atacar un "solipsismo metodológico" (PUTNAM, 1981, p. 123), que es una tesis no-realista, o verificacionista, que defiende que la verdad está relacionada de alguna manera con una aceptabilidad racional, pero que la justificación se da en términos de experiencias que cada uno de nosotros tenemos como conocimiento privado. 
¿Y la ética? En todas las Investigaciones Filosóficas Wittgenstein menciona una vez, solamente, a la ética (IF, § 77), y es en un contexto explicativo. Es decir, no se refiere a la ética propiamente dicha, pero la usa para mostrar un parecido de familia. Después volveré a este parágrafo, lo que me interesa ahora es llamar la atención que a partir de la apertura de las condiciones de significación de las Investigaciones se ha argumentado que, como ahora podemos hablar de juegos de lenguaje éticos, la significación de los términos éticos es posible (contrario al Tractatus) y ella dependerá del juego de lenguaje en el cual esté participando. Claramente, el paso a un relativismo ético es simples: si puedo participar en un juego de lenguaje que usa "correcto" o "bueno" como un principio utilitarista, y después puedo participar de un juego de lenguaje que usa ese término como un deber de la ética deóntica, esto implica que de la noción de juegos de lenguaje se sigue un relativismo ético. También puedo defender ese relativismo ético si puedo observar que dos culturas, o grupos sociales, diferentes defienden valores éticos diferentes, y hasta opuestos.

Antes de contestar algunos autores que defienden y atacan el relativismo ético a partir de Wittgenstein, intentaré definirlo primero: relativismo es la perspectiva metaética que argumenta que no existe un estándar objetivo para determinar cuál de las diferentes culturas, grupos o teorías, con diferentes puntos de vista de lo que es correcto o incorrecto hacer, es superior a otra respecto por lo menos respecto a un aspecto ético. Nótese que parto de un relativismo descriptivo (cultural, sociológico o teórico), que es muy difícil, si no imposible, negar que exista. También defino que el relativismo ético es una perspectiva metaética porque no se ubica en el nivel de la ética normativa; si este fuera el caso, el relativismo debería ser expresado en términos prescriptivos como "no se debe buscar un padrón objetivo" o "se debe buscar, aunque no exista, un padrón objetivo". Nótese que estas reglas parten de un relativismo en el nivel metaético y aceptan el relativismo descriptivo. También considero importante determinar la superioridad de uno sobre otro sea demostrada por lo menos respecto a un aspecto de los juicios morales, porque con solo que demostremos que tenemos un criterio para determinar que una cultura, un grupo o una teoría es mejor que otra aunque sea en un solo aspecto, el relativismo será vencido.

\section{Cada quien con sus reglas}


Entre los defensores del relativismo ético a partir del segundo Wittgenstein están Simon Blackburn y Richard Rorty. Blackburn defiende una teoría proyectivista que llama "casi-realismo", y en un artículo intitulado "Réplica: siguiendo reglas y el realismo moral"6, Blackburn ataca una visión neutra y realista del mundo que nos pueda demonstrar que existen estados de cosas y además de ellos, valores. La línea de argumentación de Blackburn parte de una dualidad (que atribuye a Hume, BLACKBURN, 2005, p. 163) que dice que en el mundo existen los estados de cosas y nuestras proyecciones sobre ellos. Para él, la lista de características que podemos hacer de una cosa que nosotros evaluamos como buena o correcta no tiene forma [Shapeless], y ella será influenciada por la persona que enumere esas propiedades. Si un extranjero no comparte nuestro sentido ético, no verá nada que lo haga evaluar la cosa como buena o correcta. Para Blackburn el hecho de que la lista no tenga forma iría de acuerdo con el espíritu wittgensteiniano, pues en el fondo se huye de una falsa seguridad. Para él si observamos que las diferentes agrupaciones se basan en respuestas comunes de los seres humanos, percibiremos que nunca tuvimos nada más de que eso como base, y que la construcción de un punto fijo, como un grupo de tipos de propiedades, no es nada más que eso: una grupo de respuestas con características en común.

Para Blackburn, un tipo de relativismo puede ser atribuido a Wittgenstein: "si es tu juego, entonces está correcto para ti”, (BLACKBURN, 2005, p. 171). La lectura que Blackburn hace de Wittgenstein es que este nos enseñó que el juzgamiento que haríamos del interlocutor que discuerda de nosotros al llamarlo de ciego, es de cierta manera consensual. El consenso sería necesario, y tal vez suficiente para llegar a una noción de corrección. El problema se da para Blackburn cuando no hay consenso, pues esto implica que si discrepamos de alguien, no tenemos manera de determinar cuál de los dos está correcto, lo que es común en los casos difíciles que la ética presenta, como lo demuestra el relativismo cultural o sociológico. En estos casos difíciles no podemos reducir la noción de corrección a la de consenso, pues esto implica que el consenso existía en los grupos en su ámbito interno antes de la disputa, y que el caso nuevo que se nos presenta (en el que discrepamos) no habrá corrección si no hay consenso, ipero ambos se jactarán de estar correctos! Para Blackburn, podemos defender cada uno de los grupos que están en disputa: "En un caso difícil nos encontramos con el hecho de que nuestra forma de vida, nuestras prácticas o nuestros organismos giratorios, son los 
suficientemente flexibles para ser extendidos en cualquiera de las dos direcciones" (BLACKBURN, 2005, p. 174).

Wittgenstein nos enseñó que buscar un padrón fijo es un error (IF, $\S 188$ ), pues "no tienes modelo ninguno de este hecho superlativo" (§ 192). ¿Significa esto que cada quien hace lo que le venga en gana? No, pues "no puede haber sólo una única vez en que un hombre siga una regla" (§ 199). Lo que le interesa a Blackburn es que si a partir de Wittgenstein puedo defender una postura anti-realista respecto a los hechos morales, también a partir de él puedo defender el "casi-realismo" que Blackburn propone: si no tenemos un modelo para las condiciones de verdad de una afirmación, una teoría expresivista o proyectivista puede ser aplicada a la situación (BLACKBURN, 2005, p. 175). Wittgenstein nos ayudó a rescatar nuestro derecho de pensar cosas como "verdad" y "certeza", a la vez que encaramos las fuentes antropocéntricas de nuestro pensamiento; "el problema es que parece que él nunca consiguió disipar las implicaciones relativistas y escépticas de su pensamiento", (BLACKBURN, 2005, p. 175).

Considero que Blackburn está correcto al atribuir a Wittgenstein el haber abierto mano de la posibilidad de univocidad de criterio para evaluar si una proposición es falsa o verdadera, pues en las Investigaciones debemos observar el contexto en el cual aparece cualquier afirmación para poder determinar su valor de verdad. De esta mudanza, Blackburn argumenta que Wittgenstein no se importaba con el debate entre el realista y el anti-realista, y que así como un anti-realismo va de acuerdo con su exposición, el "casi-realismo" que Blackburn quiere defender encaja muy bien. Sin embargo me parece que Blackburn pasa por alto que, si bien es cierto que Wittgenstein aceptaría que existen juegos de lenguaje en los cuales el valor de verdad no es relevante e, inclusive, aquellos en los cuales el valor de verdad no juega ningún papel del todo, el método de análisis del Tractatus puede ser observado como un juego de lenguaje más, posible, y si fuera así, argumentar a favor de un anti-realismo en las Investigaciones, me parece, está forzando mucho la flexibilización que introdujo Wittgenstein. Considero que a partir del aforismo 6.431 del Tractatus, podemos observar un tipo de realismo en Wittgenstein, y nada nos dice que esa postura mudó, pues, por ejemplo, los juegos de lenguaje científicos seguirán teniendo que preocuparse con los acontecimientos del mundo. 
Blackburn también acierta al llamar la atención de que en los casos difíciles de las disputas éticas, el problema es que no existe consenso, pero considero que esa observación lo lleva a cometer el error más grueso que es la flexibilización que le atribuye al concepto forma de vida, pues él argumenta que nuestra forma de vida es "giratoria" y permitiría que defendiéramos dos puntos éticos opuestos que se encuentren en una disputa. A partir de ahí, Blackburn también relativiza las reglas de la gramática de los juegos de lenguaje ("Si es tu juego, es correcto para ti”), y es por esta razón que es posible que el extranjero no encuentre nada compatible con su sentido ético y, ante un mismo hecho, haga un juzgamiento opuesto al nuestro. Sin embargo, pasa por alto Blackburn que la noción de forma de vida es exactamente el "punto fijo" que él le quiere quitar al realista. Wittgenstein busca dar un punto de apoyo a todos los juegos de lenguaje, y busca exponer cómo es posible que aprendamos nuestra lengua materna, así como lenguas extranjeras, y ese punto de apoyo es nuestra forma de vida porque: "Ordenar, preguntar, relatar, charlar pertenecen a nuestra historia natural tanto como andar, comer, beber, jugar" (IF, § 25).

Blackburn comete el error que cometen la mayoría de los detractores, y los partidarios, del relativismo ético a partir del Wittgenstein de las Investigaciones: como este fue omiso respecto al papel de la ética, ahora que las condiciones de significado fueron ampliadas, utilizan argumentos por analogía, pero escogen los peores términos para hacerlo. Con el ejemplo del extranjero, lo que se puede demonstrar es un relativismo descriptivo, pues el extranjero podrá observar que ante ciertos hechos, la cultura que visita hace valoraciones diferentes a la suya, entre las cuales se encuentran las valoraciones éticas (ique hacemos valoraciones éticas no aparece en ningún pasaje de las Investigaciones!). Pero, el solo hecho de que el extranjero sea capaz de entender que la cultura que visita hace juzgamientos diferentes a los suyos es posible porque comparte la misma forma de vida que la cultura que visita. La posibilidad de que el extranjero aprenda los juicios éticos que observa se da porque él puede entender e incorporar nuevas valoraciones en su sistema valorativo. De nuevo, a partir de Wittgenstein, podemos afirmar con seguridad que el extranjero aprenda un nuevo lenguaje, o nuevas costumbres, y todo esto porque comparte la misma forma de vida. Que él pueda aprender nuevos valores éticos es una aplicación de la exposición de Wittgenstein que va de acuerdo con su espíritu, y sobre todo con el libro Sobre la certeza, pero que no es explícitamente argumentado por él en ningún pasaje. Blackburn 
está correcto al decir que el "punto fijo" es bajado a la simple categoría de nuestras prácticas, pero considero que esto no es poca cosa, pues si existe punto en común respecto al cual se pueden aprender valores, y también aprender a valorar.

Las críticas a Blackburn que he expuesto atacan su línea de argumento hacia un relativismo y un escepticismo en el segundo Wittgenstein, pero no he acabado con la posibilidad de un relativismo totalmente, esto lo intentaré hacer en el último apartado.

\section{Creando juegos de lenguaje}

Richard Rorty en su artículo "Wittgenstein, Heidegger y la reificación del lenguaje", propone que mientras Wittgenstein evolucionó hacia una visión crítica respecto a los principales puntos que defendió en el Tractatus (evolución que implicó una mudanza hacía una visión pragmática) Heidegger hubiera hecho esas críticas cuando era joven, aunque poco a poco fue mudando de postura. Rorty argumenta que Wittgenstein en su segunda etapa se torna un naturalista y un pragmatista: “...el viejo Wittgenstein nos dice sobre nuestra situación respecto al lenguaje-que cuando intentamos transcenderlo al volvernos metafísicos, nos volvemos falaces $\mathrm{e}$ inauténticos", (RORTY, 1991, p. 50). Ahora no hay nada inefable y la filosofía se convirtió en un conjunto de prácticas sociales, abandonando la noción de mostrar (RORTY, 1991, p. 56). Siguiendo esta línea de pensamiento, no se puede elaborar una teoría sistemática de significado para ningún lenguaje. Para Rorty, la dirección que Wittgenstein tomó lo llevaría a dudar de la filosofía como proveedora de conocimiento, por lo que asumiría una concepción des-transcendentalizada y naturalizada de la filosofía como forma de terapia (RORTY, 1991, p. 51). Rorty caracteriza esa concepción naturalizada como aquella que defiende que cualquier explicación es causal sobre lo que es actual, y que no existen condiciones no causales de posibilidad.

Rorty termina su artículo concluyendo que el segundo Wittgenstein vio que cualquier tentativa de captar las condiciones de sentido o de expresar lo que no puede ser dicho, terminará en la creación de un nuevo juego de lenguaje. Rorty usa un parágrafo de las Investigaciones ("Pero un sonido semejante es una expresión solamente en un juego de lenguaje determinado, que entonces habría que describir”, IF, § 261) para hacer esta afirmación y concluir que Wittgenstein era un naturalista y un pragmático. Lo que Rorty quiere decir es que cualquier significación que quisiéramos usar de los signos será contextualizada, y observar cuál es el nuevo 
juego de lenguaje en el que esos signos adquieren significación y cuáles las reglas que lo regulan.

¿Qué sucedió con la ética? Haciendo referencia a un pasaje en el cual Wittgenstein le comentó a su amigo Waismann que al intentar hablar sobre ética lo único que resulta es palabrería ("Considero importante que se ponga fin a tanta palabrería [Geschwätz] sobre la ética - que si existe un conocimiento, que si existen los valores, si se puede definir el bien", WAISMANN, 1979, p. 69), Rorty argumenta que el viejo Wittgenstein se reconcilió con el hecho de lo que es palabrería [Geschwätz] y lo que no lo es, es una cuestión de grado, y abandona la esperanza de que observar el mundo, a través del lenguaje, como un todo limitado nos hará transformarnos en seres transcendentales en una experiencia mística, es una esperanza vana. La tentativa de imaginar que podemos pensar algo que no sea parte de una red de pensamientos o que podemos hablar de algo que tenga significado aunque no tenga lugar en nuestras prácticas sociales, es nuestra esperanza de buscar un lugar más allá de la palabrería [Geschwätz]. Pero para Wittgenstein, este lugar no existe pues cualquier cosa que digamos o pensemos será parte de un juego de lenguaje.

Rorty acierta en los cambios que Wittgenstein va haciendo paulatinamente, pero considero que erra al precipitarse a muchas de las conclusiones que saca de la segunda etapa del filósofo austriaco. Considero que la noción de mostrar no es abandonada del todo, como lo explique al principio de este artículo, considero que la caracterización que Wittgenstein hace del papel de la filosofía como una actividad descriptiva, así como de la gramática, prueban mi postura de que existen cosas que simplemente se deben mostrar (v.gr, las reglas constitutivas de los juegos de lenguaje).

Creo que también es un error de Rorty argumentar que la filosofía se convirtió, para Wittgenstein, en un conjunto de prácticas sociales, pues es cierto que observar las prácticas sociales se tornó una práctica de la filosofía, pero su labor no dejo de ser una aclaración de los malentendidos lingüísticos ("La filosofía es una lucha contra el embrujo de nuestro entendimiento por medio de nuestro lenguaje", IF, § 109). Por eso Rorty concluye que no se puede elaborar una teoría sistemática de significado, sin embargo se debe tener cuidado con esta afirmación, pues a pesar de que Wittgenstein se caracteriza siempre por ser un anti-teórico, muchas de las nociones que él introduce en las Investigaciones Filosóficas son teóricas. También discuerdo de la caracterización naturalizada y des-transcendentalizada que Rorty atribuye a la 
segunda filosofía wittgensteiniana, pues lo lleva a concluir que cualquier explicación es causal. Es claro que existe un rasgo pragmático en este Wittgenstein, pero reducirlo todo a un tipo de pragmatismo, me parece extremo, pues existen condiciones de significación que, desde mi perspectiva, buscan tener el carácter de transcendentales.

No concuerdo tampoco con la conclusión a la que llega Rorty de que Wittegenstein aceptara que lo que es palabrería [Geschwätz] sea una cuestión de grado, respecto a cuestiones éticas, pues no existe evidencia que me deje concluir que Wittgenstein cogitara la posibilidad de cognición de juegos de lenguaje éticos. En el pasaje al cual Rorty se refiere, Wittgenstein está criticando la ética normativa como disciplina filosófica, y su visión de filosofía en las Investigaciones es concordante con esa crítica (intentaré argumentar a favor de este punto en el siguiente apartado). Tampoco concuerdo con el abandono de la visión mística, y no creo que verdaderamente Wittgenstein pasó a ver como una "esperanza vana" el "observar el mundo como un todo limitado en una experiencia mística”. En otras palabras, si aceptamos, con todo el espíritu wittgensteiniano, la afirmación de Rorty que: “...que intentar hablar de algo que tenga significado y que no tenga lugar en nuestras prácticas sociales, es nuestra esperanza de buscar un lugar más allá de la palabrería [Geschwätz]”, esto no implica que tengamos que aceptar la afirmación de Rorty que de que “...no sobró nada inefable”. Es claro que el lenguaje nos impone límites, pero nuestra experiencia más allá del lenguaje también puede existir, y continuaría siendo inexpresable.

\section{5 ¿Es el relativismo el límite de mi mundo?}

Como la mayoría de los autores, yo concedo que a partir de la segunda etapa de Wittgenstein podemos defender un tipo de relativismo. Wittgenstein expresamente dio ejemplos al respecto (parágrafos $\S 380 Z ; \S 609, \S 610, O C$ ), pero debemos prestar atención cuál es exactamente el punto de Wittgenstein en esos pasajes, pues él nos da ejemplos de relativismo cultural para mostrarnos que en algún momento las razones que se pueden dar para fundamentar una cognición sobre otra acaban y sobra solamente la persuasión: "Al término de las razones sobreviene la persuasión. ("Piensa en lo que sucede cuando los misioneros convierten a los nativos"), § 612, OC. Inclusive dentro de una misma cultura Wittgenstein siempre aceptó que los juegos de lenguaje cambian, 
unos mueren, otros nacen (IF, $\S 23$, "Por otro lado, un juego de lenguaje cambia con el tiempo", § 256, OC).

Wittgenstein no está exponiendo el tipo de disputa que se da en cuestiones éticas, si no el desacuerdo se da en cuestiones respecto a diferentes marcos de teorización sobre los procesos de cognición ("No: es el telón de fondo heredado contra el cual distingo entre lo verdadero y lo falso", $\S 94, O C$ ). Wittgenstein, como es sabido, está llamándonos la atención de que aceptamos como verdaderas muchas proposiciones sin saber si lo son (ni cuestionarlo), así como lo hacen otras culturas con otra cosmovisión [Weltanschauung]. En otras palabras, nuestra cultura (que es en alto grado cientificista) acepta ciertas proposiciones que describen el mundo como otras culturas aceptan sus propias mitologías ("Las proposiciones que describen esta figura del mundo podrían integrar una especie de mitología. Y su papel es como el de las reglas de un juego; y el juego puede ser aprendido puramente en la práctica, sin aprender regla explícita alguna”, § 95,OC).

Wittgenstein está desarmando nuestra creencia de que existe un suelo "duro" y "firme" como base para construir nuestro conocimiento proposicional(¡!): el "lecho del río" cambia algunas veces, y las proposiciones que lo conforman pasan a ser proposiciones de la "corriente del río" y viceversa (§ 96, § 97, § 99 OC). Y, atacando sus viejos pensamientos, argumenta que las proposiciones lógicas (así como cualquier otra) puede ser vista como una proposición empírica en unas ocasiones, y en otras como la "regla" con la cual se examina $(\S 98, O C)$. Este último parágrafo prueba que la visión del Tractatus pasó a ser una posibilidad más de significación que no fue abandonada totalmente. El error se comete al pensar que es la única. Lo que me interesa en este momento es llamar la atención de que Wittgenstein en su exposición sobre el relativismo descriptivo (ya sea cultural o sociológico) está mostrándonos que la manera por la cual valoramos ciertas proposiciones como verdaderas, puede mudar, o sea, que el método de valoración es ¡relativo! Por eso llamo a este tipo de relativismo, que va de acuerdo con las Investigaciones, de relativismo epistemológico.

En otro lugar, Wittgenstein llama esas proposiciones en las cuales se basan las otras de "bisagras" ( $\S 341, O C$ ), y esto ha llevado a varios teóricos a argumentar que algunas proposiciones éticas se comportan como esas proposiciones bisagra, en la cuales las otras se apoyan. En ese sentido, Wisnewski por ejemplo distingue las "explicaciones" de las "descripciones", siendo estas segundas las proposiciones que 
muestran aquellas proposiciones bisagra, que son reglas constitutivas del juego de lenguaje ético; mientras que las "explicaciones" son aptas de ser valoradas como verdaderas y depende de aquellas (WISNEWSKI, 2007). Wisnewski llama a este tipo de ética "ética clarificativa". Concuerdo con él respecto a su distinción entre "explicación" y "descripción", que en el fondo es una extensión de la distinción entre decir y mostrar, pero no concuerdo con la equiparación de Wisnewski entre el conocimiento perceptual y el conocimiento moral (WISNEWSKI, 2007, p- 112 y ss). Pero discuerdo mucho más, lo que interesa a este artículo, a la aplicación de las noción de proposiciones bisagra en el ámbito de la ética, intentaré exponer el porqué en los siguientes párrafos.

Debe notarse que Wittgenstein en ningún momento está haciendo referencia a valores éticos, y creo que aquí radica uno de los errores comunes que realizan los interpretes de Wittgenstein, pues él está tratando de valoraciones pero ¡de sentido!, y hacer la analogía para valoraciones éticas parece ser un paso simple. De este paso es del cual discuerdo. Considero que Wittgenstein no lo hizo. Antes quisiera llamar la atención que en la nomenclatura wittgensteiniana, él evitó llamar la asignación de valores de verdad de las proposiciones como una valoración, y siempre que se refirió a la ética lo hizo en términos de valor. Considero este punto no de poca importancia, ya que al determinar si una afirmación se sigue de otra, o si ella es verdadera conforme una realidad, estamos haciendo una valoración que, aunque no es ética, es cognitiva. Obsérvese, por ejemplo, cuando él propuso un borrador del prefacio de las Observaciones Filosóficas escribió: "El espíritu de esta civilización, se hace manifiesto en la industria, la arquitectura y la música de nuestro tiempo, en su fascismo y socialismo, y es ajena y no es congénito al autor. Este no es un juicio de valor. No lo es, es verdad,..." ( $C V$, p. 6e). Wittgenstein está diciéndonos que no es un juicio ético, es simplemente una descripción.

Si tenemos eso en mente y recordamos que Wittgenstein caracterizó la ética como: "la investigación de lo que es valorizado, o, de lo que es verdaderamente importante, o..., del significado de la vida, o de lo que hace la vida valer la pena ser vivida, o de la manera correcta de vivir" (LE, p. 1), podemos observar que una ética inefable, y una visión mística de la misma, es coherente con su segunda etapa, y sobre todo con el relativismo epistemológico que caractericé anteriormente.

Si recordamos una serie de aforismos y comentarios respecto a los valores en su primera etapa, podemos observar cómo son caracterizados esos valores que son 
conocidos como la "ética": el sentido del mundo reside fuera de él (TLP, 6.41), el mundo de los felices es distinto del de los infelices y esto es así, no porque cambie el mundo, pero porque cambian las valoraciones (TLP, 6.43), para lo que es Superior [Höhere] resulta totalmente indiferente cómo sea el mundo. Dios no se revela en el mundo (TLP, 6.432). Hasta aquí no hemos visto nada nuevo, a no ser que podemos pensar en una dualidad entre los estados de cosas y los valores.

Pero Wittgenstein no nos dice solamente esto, pues la ética no es simplemente "la investigación de lo que es valorizado" también es la investigación "del significado de la vida [...] o de la manera correcta de vivir”. ¿Cuál es la manera correcta de vivir? Wittgenstein nos da algunas pistas. En la entrada su Diario del 06 de julio de 1916 escribió: "En ese sentido Dostoievsky está correcto cuando él dice que el hombre que es feliz está realizando el propósito de su existencia”. Pero, de nuevo ¿cuál es el propósito de la existencia? En el Tractatus quien intentase decir cuál es ese propósito incurría en un contrasentido: “№ es ésta la razón de que los hombres que han llegado a ver claro el sentido de la vida después de mucho dudar, no sepan decir en qué consiste este sentido?” (TLP, 6.521). Así es que se aclara que Wittgenstein está atacando la ética como intento filosófico de discursar sobre esos temas $y$, es en ese sentido, que denomina esas tentativas de palabrería [Geschwätz].

En una entrada del Diario Wittgenstein nos había dado otra pista respecto a qué es lo ético. El 07 de octubre de 1916 escribió: "La obra de arte es el objeto visto sub specie arternitatis; y la vida buena es el mundo visto sub specie aeternitatis. Esa es la conexión entre arte y ética". Recordemos que en el Tractatus él nos dijo que "la estética y la ética son lo mismo" (TLP, 6.421). Pero, ¡de nuevo!, ¿qué significa ver el mundo sub specie aeternitatis? "La visión del mundo sub specie aeterni es su contemplación como un todo -limitado-. Sentir el mundo como un todo limitado es lo místico". (TLP, 6.45). Otra vez leemos que es "ver el mundo", pero esta vez como un todo limitado. Haciendo un resumen de todo lo que está escrito en el Tractatus podemos deducir que el mundo es la totalidad de los hechos, y que lo que es Superior no se importa con lo que sucede en el mundo, eso que es Superior pertenece a lo místico, así como la ética pertenece a lo místico ¿Cómo es una experiencia ética mística? Primero, el percatarse que el significado de la vida no pertenece al mundo, y segundo, que cuando experimentamos el significado de la vida o "lo que hace la vida valer la pena ser vivida", no lo podemos expresar. 
En las conversaciones con Waismann, con fecha de noviembre de 1930, leemos: "Lo ético no se puede enseñar. Si, mediante una teoría, pretendiera explicar al otro en qué consiste la esencia de lo ético, lo ético carecería de valor.” (WAISMANN, 1979, p.117). Antes de concluir que una "teoría no tiene valor", Wittgenstein explica que lo único que se puede hacer es hablar en primera persona, lo que no implica un subjetivismo, esto lo que significa es que lo único que se estaría relatando es una experiencia, y que teorizar sobre esa experiencia era lo que Wittgenstein condenaba. Es por todo lo expuesto hasta aquí que considero que Wittgenstein ve lo ético como una experiencia mística, y que lo máximo que se puede hacer es mostrar por medio del ejemplo, y nada más. Y esta es la razón por la cual para Wittgenstein en ética (y en religión) se están usando constantemente símiles. El problema se da cuando se cuestiona respecto al hecho con el cual es construido el símil, pues el símil debe estar representando un hecho. Cuando se busca el hecho que está siendo representado mediante el símil, me doy cuenta de que ese hecho no existe, y es el momento en el que se toma consciencia de que lo que parecía un símil, era en realidad un contrasentido.

Considero que esta postura va de acuerdo con la visión de las Investigaciones Filosóficas. Veamos los parágrafos en los cuales Wittgenstein hace referencia a la ética: a partir del parágrafo $§ 75$, Wittgenstein está argumentando en contra de la necesidad de tener que dar una definición clara y precisa sobre el concepto de juego. Para él, mostrar los parecidos de familia entre los diferentes juegos, nos haría observar que son juegos. Para ilustrar su punto, en el parágrafo $§ 76$ utiliza la metáfora de la figura $[$ Bild $]$ para argumentar que ante la tentativa de definición, alguien puede dibujar una figura y yo discrepar de ella, aunque yo acepte que por ahí va la cosa; así como alguien puede trazar una figura nítida, y no ser la que yo había imaginado. Mi imagen es de una figura difusa con manchas de colores, la que se me presenta es una figura con manchas de colores, pero claramente delimitadas. "El parentesco es, pues, tan innegable como la diferencia" (IF, § 76). Es decir, ambas tentativas son válidas pues tienen cosas en común (parecidos de familia), así como diferencias. Ya en el parágrafo $\S 77$, Wittgenstein nos advierte que el grado de semejanza entre la figura nítida y la figura borrosa depende de cuán borrosa sea la segunda. Si la figura es muy borrosa, parece que puedo trazar casi cualquier cosa que quiere que se le parezca al trazar la figura nítida ("Vale todo y nada".). Pero ese es el punto central de Wittgenstein en estos pasajes. ¡No! La figura borrosa, aun siendo borrosa, me da ciertos padrones para poder trazar una o varias figuras que se le 
parezcan. Y aquí aparece el comentario que nos interesa: “-Y en esta posición se encuentra, por ejemplo, quien, en estética o ética, busca definiciones que correspondan a nuestros conceptos", (IF, § 77). Debemos notar que Wittgenstein en este pasaje no hace alusión a cómo se debe vivir, o a lo que es valorizado, a lo que es verdaderamente importante, al significado de la vida, ni a lo que hace la vida valer la pena ser vivida. No, más parecido con una definición mooreana de la ética, nos está diciendo que un ejemplo de un caso en el cuál tenemos una figura borrosa, y queremos dibujar una nítida y clara, es cuando en ética queremos definir nuestros conceptos ("bueno", "correcto", etc): trazaré figuras con parecidos de familia y eso es todo a lo cual puedo aspirar. ¿Por qué? Porque he aprendido esas palabras a partir de EJEMPLOS, en ciertos juegos de lenguaje (IF, § 77). Si aprendemos las reglas de los juegos de lenguaje en sus usos, como costumbres (IF, § 199), así las utilizaremos. Esto no significa que estemos expresando el sentido ÉTICO de la palabra "bueno" o "correcto". Las utilizamos con parecidos de familia con otras personas que las utilizan también.

¿Implica esto un subjetivismo? Si los juegos de lenguaje son prácticas que no se pueden jugar en privado, la respuesta es negativa. ¿Puedo defender un escepticismo? No, porque no "vale todo y nada”. ¿Relativismo? La respuesta es la misma: ¡no! Considero que Wittgenstein aquí está defendiendo que los conceptos éticos se usan como ellos fueron aprendidos (como si fueran figuras nítidas), pero después de analizar bien el juego de lenguaje en el cual se está empleando ese concepto veremos que son figuras difusas, porque "el sentido de la vida" continúa siendo inexpresable. No encuentro ningún pasaje en las Investigaciones que me demuestre que Wittgenstein abandona su postura respecto a la ética ni a lo místico. Considero que ella continúa siendo inefable, que se puede mostrar por el ejemplo, y que la experiencia mística es una experiencia que difiere de la experiencia cognitiva.

Aquí se puede responder con dos contraargumentos: el primero diría que, ante la posibilidad de expresión que la multiplicidad de los juegos de lenguaje, alguien puede muy bien acertar en algún momento y expresar "el sentido de la vida". La respuesta es otro argumento contra el relativismo, que ya expuse anteriormente. Existe un punto fijo y común a todos los seres humanos: su forma de vida. Puedo trazar como común denominador que para todos ellos el "sentido de la vida" sea una experiencia mística e inefable y que, al compartir la misma forma de vida, sus limitaciones son las mismas. 
El segundo contraargumento se puede construir a partir de mi respuesta al primero: aceptar que existe lo místico implica que, además de un relativismo epistemológico, debo admitir un relativismo cognitivo o epistémico, al aceptar que hay cosas que se conocen, otras que no, y que hay diferentes modo de conocimiento. Esto lo tengo que conceder, pero no destruye verdaderamente mi ataque al relativismo ético a partir de Wittgenstein. Que hay varios modos de conocer puede ser encontrado en las Investigaciones (v. gr.: $§ 150$ ), pues conocer por ejemplo cuánto metros tiene Mont Blanc (IF, § 78) es diferente a conocer cuál es la regla que debo aplicar en algún lance de un juego de lenguaje. Pero también se debe tener cuidado con no mezclar reglas de un juego con reglas de otro. Por ejemplo, comete un error quien al conversar sobre Sherlock Holmes lo hace creyendo que habla de una persona existente (juego de lenguaje descriptivo) con quien sabe que es un personaje creado por Sir Arthur Conan Doyle (juego de lenguaje ficticio). Puedo aceptar un relativismo respecto a las diferentes posibles experiencias del ser humano (que su forma de vida permite) unas pueden ser cognitivas, otras místicas, y de otros tipos. Nuestra capacidad de expresión de ellas puede ser limitada en algunos casos (como es el caso de la ética según mi criterio); y nuestra capacidad de expresión de aquellos casos que podemos expresar puede cambiar de cultura a cultura, o de grupo a grupo.

\section{Conclusión}

Nada de lo escrito en el último párrafo va en contra de la lectura de la forma de vida como una extensión del "yo" transcendental del Tractatus, ni en contra de mis argumentos contra el relativismo ético defendido a partir de las Investigaciones Filosóficas. Es por esta razón que considero que la respuesta a la pregunta del título es afirmativa, pero debe ser bien explicada: mi cultura condiciona mi visión del mundo, pero el límite verdadero lo impone mi forma de vida, que así como me permitirá conocer (y entender) otras culturas, limitará mi cognición a ciertos ámbitos y me imposibilita la cognición de otros. Y todo esto expresado en el plural de la primera persona: ¡nuestra forma de vida y nuestra cultura limita mis posibilidades y mis capacidades de cognición!

Considero que esta posición sirve a la metaética en cuando posibilita un relativismo epistemológico, pero coloca un límite a la ética normativa; va de acuerdo con la visión de valores absolutos de Wittgenstein; y finalmente rechaza la posibilidad 
de halar de proposiciones "bisagra" en el sentido de la ética como la entendía Wittgenstein. Si estas proposiciones "bisagra" existieran, lo que haría sería contextualizar el valor de verdad de ciertas proposiciones y ante un buen examen nos percataríamos que estamos frente a valores relativos, de acuerdo a la Conferencia sobre ética, o sea, no estaríamos expresando los valores absolutos que competen a la ética. 


\section{Notas}

${ }^{1}$ Doctorando del Programa de Posgrado en Filosofía de la Universidade Federal de Santa Catarina, Florianópolis, S.C., Brasil. e-mail: jonathao@hotmail.com

${ }^{2}$ WITTGENSTEIN, Briefe an Ludwig von Ficker.

3 “El punto central del libro es ético. En cierta ocasión quise incluir en el prefacio una frase que de hecho no se encuentra en él, pero que la transcribiré para usted aquí, por acaso encuentre usted en ella una clave de la obra. Lo que quise escribir, pues, era esto: Mi trabajo consiste de dos partes: la presentada aquí más todo lo que no he escrito. Y es precisamente esta segunda parte la más importante. Mi libro traza los límites de la esfera de lo ético, por así decirlo, desde adentro y estoy convencido de que esta es la ÚNICA manera rigurosa de trazar esos límites". WITTGENSTEIN, Briefe an Ludwig von Ficker, p. 35. Apud. JANIK, A. y TOULMIN, S, 1983, p. 243. (Resaltado nuestro).

${ }^{4}$ WILLIAMS, Bernard. Moral Luck. New York: Cambridge University Press, 1991, p. 144 y ss.

${ }^{5}$ PUTNAM, Hilary. Reason, Truth and History. New York: Cambridge University Press, 1981.

${ }^{6}$ BLACKBURN, Simon. "Reply: Rule-following and Moral Realism” In: HOLZTMAN, Steven; LEICH, Christopher (Ed.) Wittgenstein: to Follow a Rule. Boston: Routledge, 2005.

7 "Wittgenstein, Heidegger and the Reification of Language" en RORTY, Richard. Essays on Heidegger and other philosophical papers. Vol. 2. New York: Cambridge University Press, 1991. 


\section{Bibliografía}

BOUWSMA, O.K. Wittgenstein: últimas conversaciones 1949-1951. Trad. Miguel Ángel Quintana Paz. Salamanca: Ediciones Sígueme: 1986.

HOLZTMAN, Steven; LEICH, Christopher (Ed.) Wittgenstein: to follow a rule. Boston: Routledge, 2005.

JANIK, Allan S. y TOULMIN, S.E. A Viena de Wittgenstein. Trad. Álvaro Cabral, Rio de Janeiro: Campus, 1991.

PITKIN, Hanna Fenichel. Wittgenstein and justice. Berkeley: University of Califórnia Press, 1993.

PUTNAM, Hilary. Reason, Truth and History. New York: Cambridge University Press, 1981.

RORTY, Richard. Essays on Heidegger and other philosophical papers. Vol. 2. New York: Cambridge University Press, 1991.

WAISMANN, Friedrich. Ludwig Wittgenstein and the Vienna Circle. Ed. B.F. Guinness. Oxford: Blackwell, 1979.

WILLIAMS, Bernard. Moral Luck. New York: Cambridge University Press, 1991.

WISNEWSKI, J. Jeremy. Wittgenstein and Ethical Inquiry: a defense of ethics as clarification. London: Continuum International Publishing Group, 2007.

WITTGENSTEIN, Ludwig. [CV]Culture and value. Ed: G.H. von Wright; Trad. Peter Winch. Oxford: Basil Blackwell, 1977.

. [IF] Investigaciones Filosóficas. Trad. Alfonso García Suárez y Ulises Moulines. Barcelona: Editorial Crítica: 2008.

Review 74 (1965) 3-12.

[LE] "Wittgenstein's Lecture on Ethics", in: The Philosophical

. [NB]Notebooks 1914-1916. Ed. by G. H. von Wright and G. E. M.

Anscombe. Trad. G. E. M. Anscombe. Oxford: Basil Blackwell, 1961.

[OC]On Certainty. Org. G. E. M. Anscombe; G. H. von Wright; Trad. G.E.M. Ascombe y Denis Paul. Oxford: Blackwell Publishing: 1975.

[TLP]Tractatus Logico-Philosophicus. Trad. Luis M. Valdés Villanueva; 3ra edición. Madrid: Editorial Tecnos, 1994.

México: UNAM, 1979.

[Z]Zettel. Trad. de Octavio Castro y Carlos Ulises Moulines). 